\title{
Model test study on landslide of reservoir bank near dam under
}

\section{antecedent rainfall}

\author{
LI Zhuo ${ }^{a, b,{ }^{*}}$, HE Yong-jun ${ }^{\text {a, b }}$,XU Hai-feng ${ }^{a, b}$, YANG Yang ${ }^{a, b}$
}

a.Dam Safety Management Department, Nanjing Hydraulic Research Institute, Nanjing 210029, China;

b. Dam Safety Management Center of the Ministry of Water Resources, Nanjing 210029, China)

Key words: Antecedent rainfall; slope; landslides; model test

Abstract: Based on the rainfall profile in the area of the reservoir bank near the dam of Longjiang hydropower plant in Yunnan Province, the authors investigate the landslide under antecedent rainfall. By using the self-developed experimental apparatus, a model test which simulate the landslide under antecedent rainfall in laboratory have been conducted and the characteristics of the landslide under the antecedent rainfall have been investigated. The research shows that the antecedent rainfall is a major factor of the landslide. The antecedent rainfall infiltrates into the slope from the slope surface which reduces the soil strength so that the rainfall in the later time could easily initiate the landslide. The loss of or reduction of suction in the slope caused by the antecedent rainfall, which is the major reason for the landslide, and this kind of landslide is categorized into shallow retrogressive landslide.

\section{Introduction}

Landslides caused by the major factor including rainfall, eater level, earthquake and improper man-made development et al. landslide disaster is the most common by rainfall, Rainfall is one of the most significant triggering factors for slope failure occurrence in China. The mechanisms by which rainstorms can lead to slope instability in the unsaturated zone in the weathered igneous rock profiles include rainfall infiltration, percolation in the unsaturated part of a slope, and saturated groundwater flow resulting in rise in groundwater tables.

Landslides disasters of slope have risen in China since $20^{\text {th }}$, which is typical and representative in the word. Serious landslide disasters have occurred in China, with the exception of Shandong province. According to statistics, more than 400 city and 10000 villages were infringed by the landslide disaster, it affected a total area of $1.73 \times 10^{6} \mathrm{~km}^{2}$, accounting for $18 \%$ of the area of China. 
Serious landslide disaster not only caused great losses of life and property for the local residents, also destroyed a number of factories and mines, and seriously affects the railway, highway, water transportation and infrastructure security operations such as reservoir.

The stability of slopes is seriously affected by rainfall, because the shear strength that is present in unsaturated soils due to matric suction is lost as a result of rainwater infiltration into the soil. However, antecedent rainfall caused the landslide research is less, the Hong Kong, Italy, Singapore, Pyrenees region of relations between the rainfall and landslide were studied, respectively(Brand et al.,1984, Brand et al.,1992;Pitts.,1985.,Aleotti.,2004), the results showed that landslides not caused by antecedent rainfall, Singapore landslides shows that antecedent rainfall is the key factor of landslide (Tan et al.,1987), one of the most convincing evidence is Bukit Batok landslides(Rahardjo et al., 2008). Tan (LI et al.,2013)based on the observed data of the three gorges reservoir area, such as research of antecedent rainfall on soil slope stability, the influence of different studies have shown that antecedent rainfall there is a certain relationship.It has been recognized in the literature that antecedent rainfall can be a predisposing factor in the activation of soil slips(Wieczorek,1987). The influence of antecedent rainfall is difficult to quantify as it depends on several factors, including the heterogeneity of soils(strength and permeability properties) and the regional climate. In tropical areas, for example, antecedent rainfall is not an important factor (Brand, 1992) as well as in slopes cover with coarse colluvium having large interparticle voids, debris flows can occur without significant antecedent rainfall (Corominas and Moya, 1999). Similar response can be observed even in pervious soils due to the presence of preferential groundwater passageways (macropores, animal burrows, root channels)(Corominas,2000). On the contrary, in low-permeability soils antecedent rainfall can be an important factor because it reduces soil suction and increase the pore-water pressures in soils. However, the time interval established as significant by the various authors differs considerably: 5 days (Wieczorek et al., 2000), 10 days (Crozier, 1999; Glade et al., 2000), 15 days (Govi et al., 1985). Landslides dams usually form in mountainous areas of high terrain (Costa and Schuster, 1998), rainfall-induced shallow slope failures are among the most devastating natural disaster in areas. The antecedent rainfall triggered more than 2000 landslides of China.

In this paper, based on antecedent rainfall effect of Longjiang hydropower station in Yunnan of China as an example, in this background, the authors designed model test apparatus of landslide in the laboratory. The landslide experimental apparatus is introduced, the landslide caused by 
antecedent rainfall effect is studied through model test cause landslide characteristics.

\section{Experimental investigation}

\section{Model test development}

The landslide experimental apparatus is independently developed by us, the testing apparatus is made up of main box body, rainfall system, water system, data acquisition system and high speed camera, in order to facilitate the process of observation of the slope deformation and landslide body, on the side of both sides of the model box set high transparent organic glass window visible, real-time observations during the test inside the slope and lateral deformation, displacement situation. Model test box size $700 \mathrm{~cm} \times 200 \mathrm{~cm} \times 200 \mathrm{~cm}$ (length $\times$ width $\times$ height), model box is divided into three parts, Model test box I for drainage, Model test box II for the production of the slope, Model test box III to simulate the water table.

\section{The apparatus and instrument embedment}

In this study, model test main instruments included piezometers, earth pressure osmometers, tension meters, high speed camera, and rotary sampler. 5 earth pressure osmometer were buried at the bottom of model test box II(Fig.1), which is buried deeply $170 \mathrm{~cm}, 5$ earth pressure osmometers connected to the acquisition system respectively, acquisition system time interval data collected a $10 \mathrm{~min}$. There are five tensions meter, two tension meters arranged at the top of the slope (Fig.2), three tension meters arranged on the surface of slope, three tension meters along the slope surface is arranged in a liner. Nine piezometers were buried at the bottom of model test box (Fig.3), 2 piezometers is buried deeply $120 \mathrm{~cm}$, nine osmometers respectively connected to the acquisition system, acquisition system to gather a 10 min interval data. Z5 Z1, Z2, Z3 and Z4 deeply, respectively is $150 \mathrm{~cm}, 150 \mathrm{~cm}, 20 \mathrm{~cm}, 20 \mathrm{~cm}, 60 \mathrm{~cm}$, tension meter Z5 buried deeply $60 \mathrm{~cm}(60 \mathrm{~cm}$ model corresponding to the slope top location).High-speed cameras arranged in front of the model test on one side of the box, the real-time image acquisition. T1、T2、T3、T4 and T5 for earth pressure osmometers, Z1、Z2、Z3、Z4 and Z5 for tension meters, S1、S2、S3、S4、S5、S6、S7、S8、 S9、S10、S11 for piezometers. 


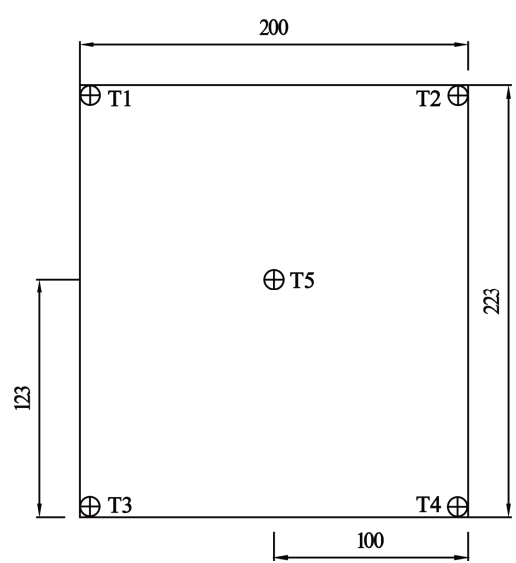

Fig.1 Layout of earth pressure(unit:cm)

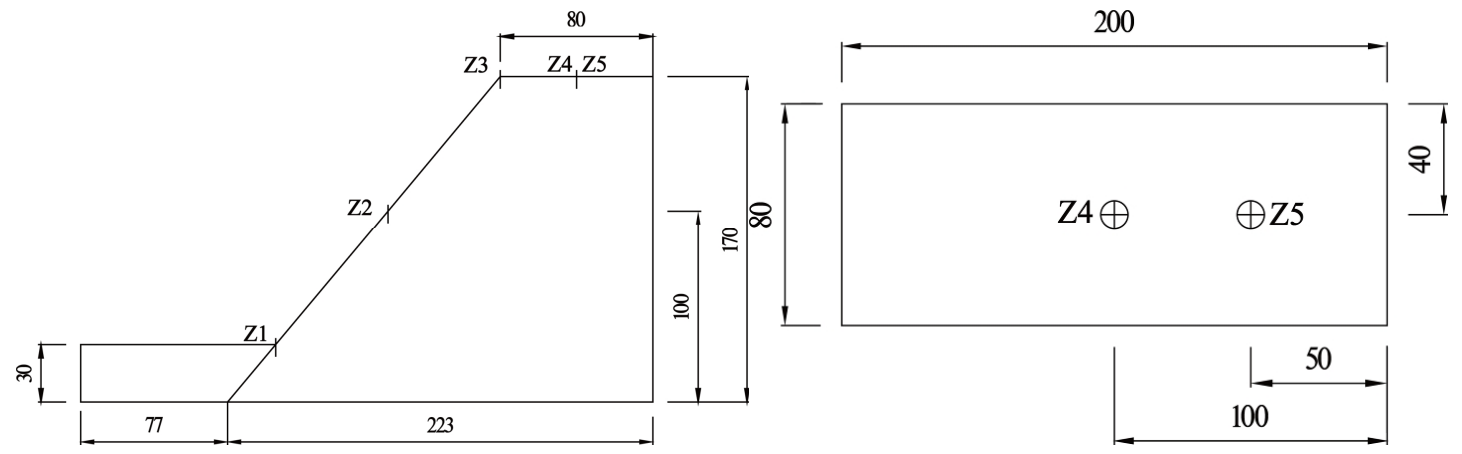

(a)

(b)

Fig.2 Layout of tonometer(unit:cm)

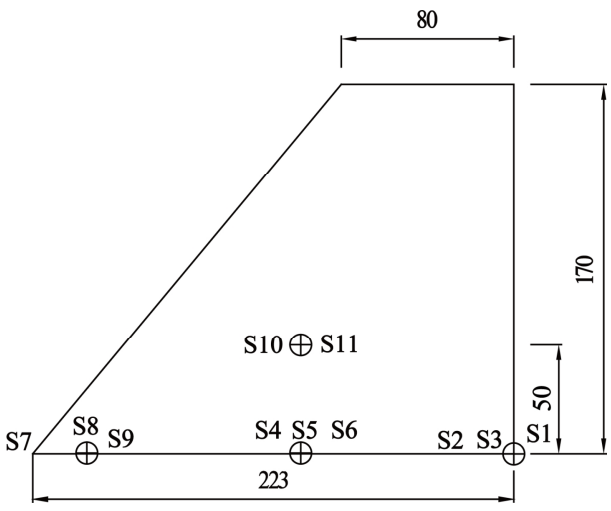

(a)

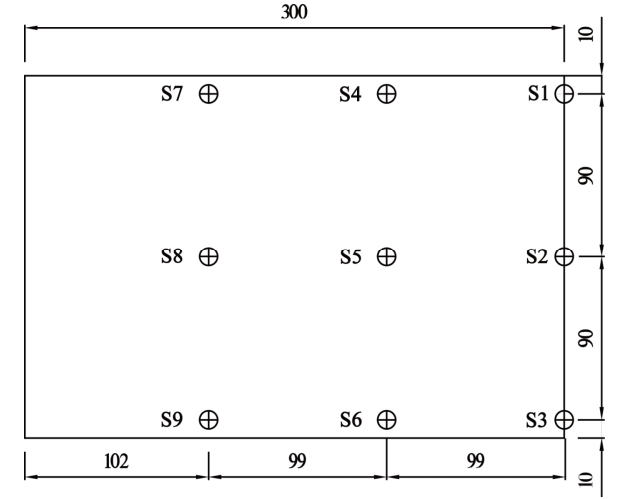

(b)

Fig.3 Layout of pore-water pressure(unit:cm)

\section{Specimen preparation}

Water content, density and the permeability coefficient of the tested clayey soil in this study were $19.5 \%, 1.686 \mathrm{e}-05 \mathrm{~cm} / \mathrm{s}$ and $1.70 \mathrm{~g} / \mathrm{cm}^{3}$, respectively. Model test of slope is a homogeneous slope, the slope Angle of $50^{\circ}$, the rainfall intensity was $70 \mathrm{~mm} / \mathrm{h}$, and the amount of rainfall was designed according to the maximum daily rainfall in Yunnan and other loess plateaus near the monitoring site in the past 20 years. The experimental samples were taken from landslide of soils the Longjiang hydropower station in Yunnan province of China. The inner walls of the box were covered with Vaseline to reduce the effect of the samples. The prepared samples were placed in box 
II, the length, width and height model of slope were $\mathrm{L} \times \mathrm{W} \times \mathrm{H}=300 \mathrm{~cm} \times 200 \mathrm{~cm} \times 170 \mathrm{~cm}$ (Fig.4., Fig.5)
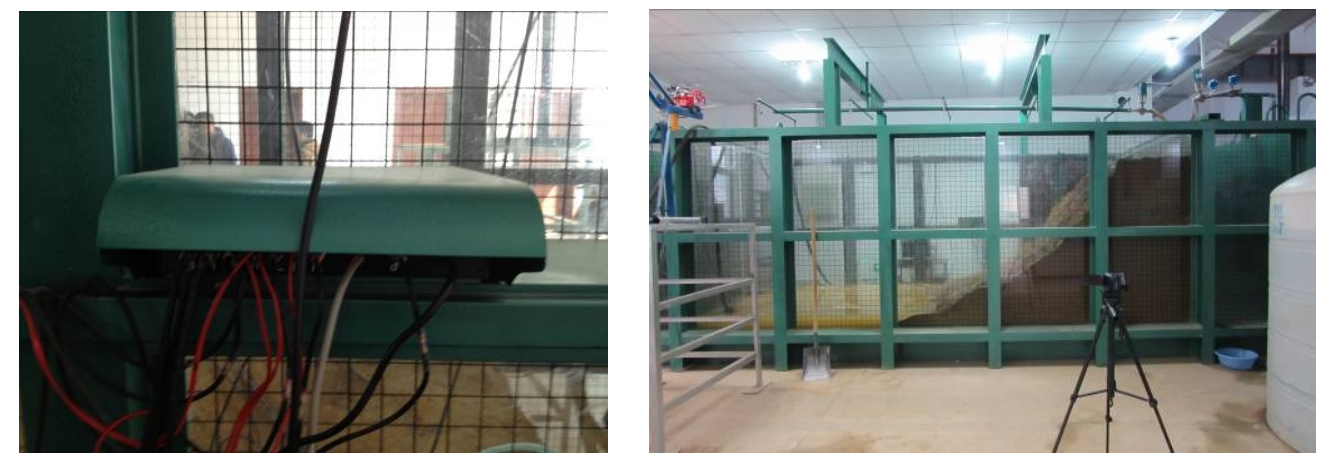

Fig.4 Landslide slope experimental apparatus in the laboratory

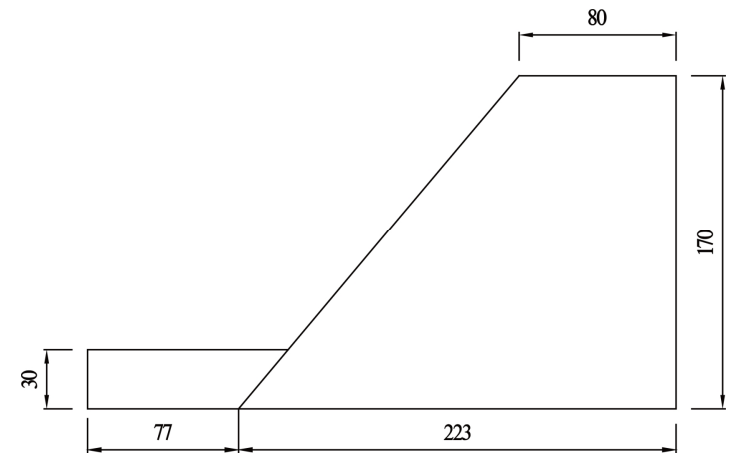

Fig.5 Sizes of physical model of landslide(unit:cm)

\section{Result and discussion}

Rainfall is the major inducing factors of the slope of landslides, for the slope instability mechanism caused by rainfall factors, the current common understanding: rainfall caused the slope infiltration of underground water level rise, the softening of the soil sliding surface, which reduces the slope stability, and lead to the occurrence of landslide.

Surficial failure is most often addressed by an infinite slope stability analysis, as reviewed below. However, the effective cohesion plays an inordinate large role in calculation of the factor of safety by the classical infinite slope analysis. It will be shown that effective cohesion does not exist in non-cemented soils, but rather the failure envelope for soils is curved, and this may be correctly accounted for in the infinite slope stability analysis employed for surficial stability. Finally, experiments on water infiltration into a soil slope performed by $\mathrm{Ng}$ and Zhan (2007) are used to indicate the mechanics leading to surficial instability of soil slopes. The mechanism of rainfall induced slope failure is as follows: rainfall infiltration results in a reduction of matric suction in soil which in turn reduces the soil shear strength, and subsequently triggers the slope failure (Li et al., 2005). Furthermore, heavy downpour may cause a perched water table with positive pore-water pressure develops in the soil slope, which will further decrease the shear strength of soil and 
eventually make the slope increasingly susceptible to failure.

For the study of antecedent precipitation caused by landslides, model test study of arising under the action of antecedent precipitation characteristics of landslide, antecedent precipitation under the action of landslide model test as shown in Fig. 6.

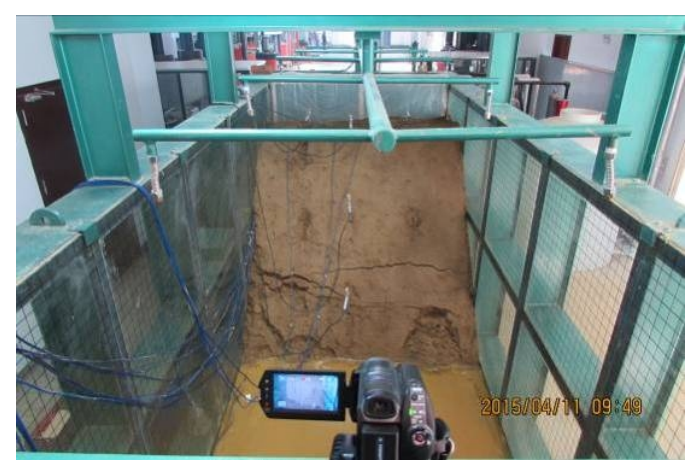

(a)

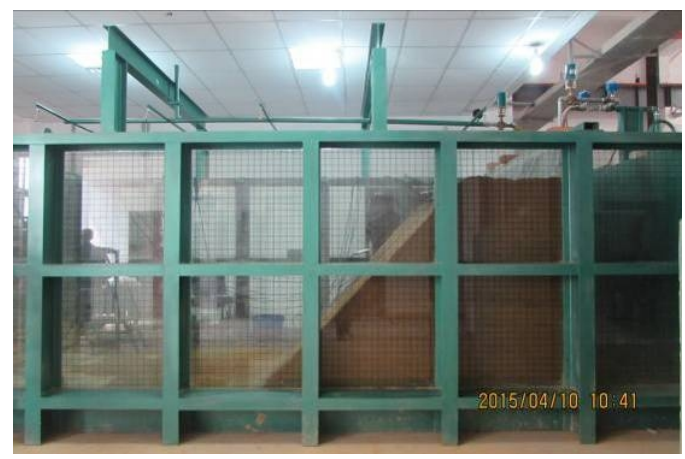

(c)

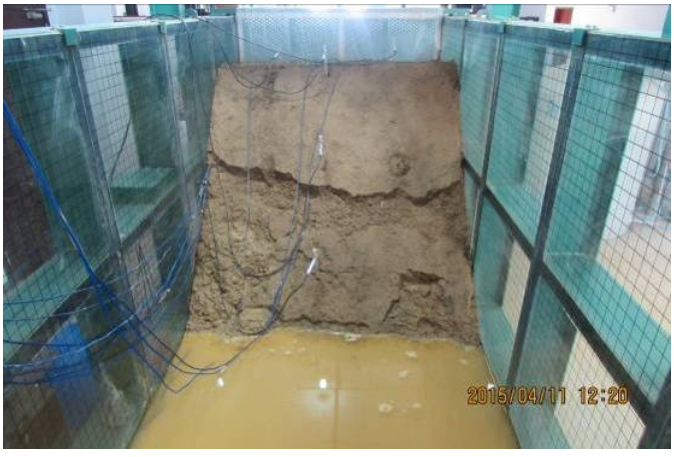

(b)

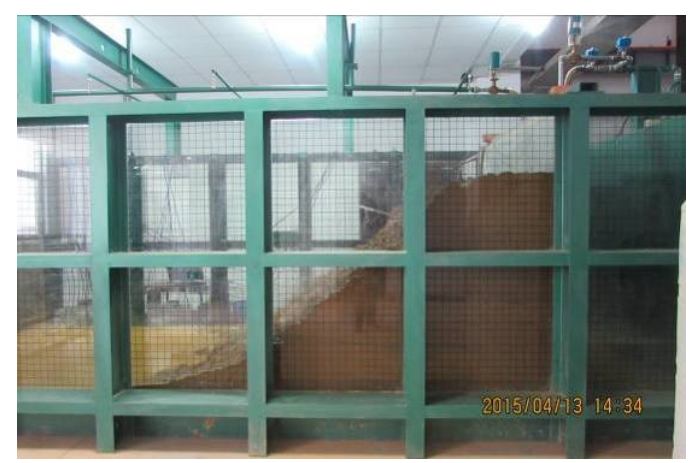

(d)

Fig.6 Landslide slope under antecedent rainfall

\section{earth pressure changes for antecedent rainfall}

Many researchers have studied the impact of landslide on slope. However, the efforts of previous researchers have been concentrated primarily on rainfall, with considerably less focus on antecedent rainfall. The result in Fig.7 illustrates the variability of soil earth pressure with respect to time along the surface of failure under antecedent rainfall. Earth pressure T1、T4、T5 represented by analysis, when antecedent rainfall $58 \mathrm{~h}, 103 \mathrm{~h}$ and $153 \mathrm{~h}$, rainfall duration $0.7 \mathrm{~h}, 0.25 \mathrm{~h}, 2 \mathrm{~h}$, respectively, 3 rainfall intensity is $70.0 \mathrm{~mm} / \mathrm{h}$. The earth pressure with an increasing number of antecedent rainfall, this is because rainfall infiltration caused the slope of weight increasing, Slope landslide happened after 153h, earth pressure of T1、 earth pressure of T5 decreasing. However, earth pressure of T4 increasing after rainfall, earth pressure T4 is mainly caused by landslide. 


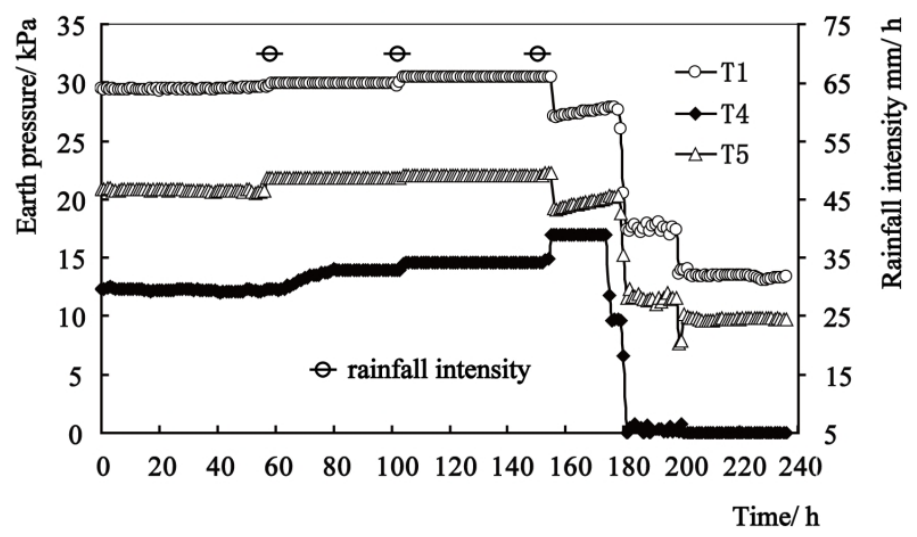

Fig.7 Variations of earth pressure under antecedent rainfall

\section{Pore-water pressure changes for antecedent rainfall}

Pore-water pressure for slope, shown in Fig.6, indicate that the pore-water pressure of S8 increasing with number of antecedent rainfall. Pore-water pressure of S7、 Pore-water pressure of S8、 Pore-water pressure of S9 have changed under the action of antecedent rainfall, other six pore-water pressures unchanged. Pore-water pressures of S8 have changed after 120h, Pore-water pressures of S8 in this study was $0.62 \mathrm{kPa}$. The analyses mention above illustrates that antecedent rainfall caused landslide of slope.

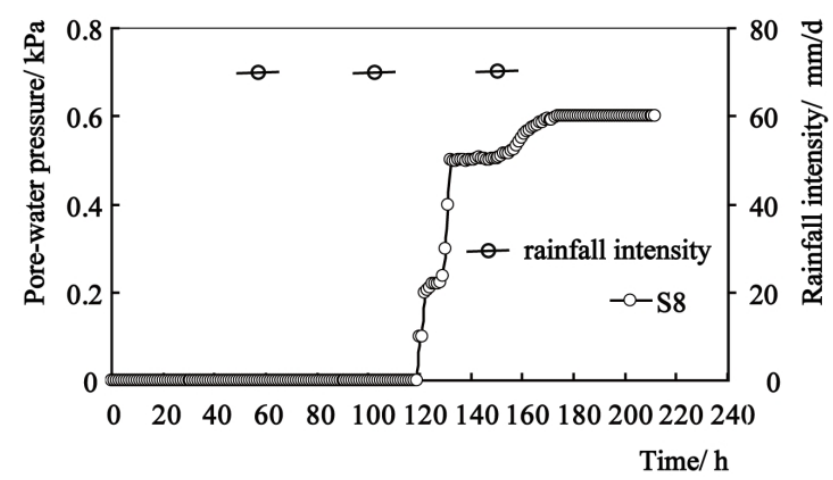

Fig.8 Variations of pore-water pressure under antecedent rainfall

\section{Matric suction changes for antecedent rainfall}

Antecedent rainfall is the key factor that induced landslide, as a result, causes by the wetting front moves down in a loss of the slope matric suction, leading to reduced stabilizing force, down force is increased until instability.

To investigate matric suction changes under antecedent rainfall of slope, Fig.9 shows the suction distribution as the result of antecedent rainfalls of $58 \mathrm{~h}, 103 \mathrm{~h}$ and $153 \mathrm{~h}$ in the laboratory. Matric suction were $-41 \mathrm{kPa}$ of tension meter $\mathrm{Z} 1$ 、 tension meter $\mathrm{Z} 2$ 、 tension meter $\mathrm{Z} 3$ 、 tension meter Z4 tension meter Z5 before antecedent rainfall,matric suction decreasing with the number of 
antecedent rainfall, matric suction decreased of tension meter Z1 until 98h, because antecedent rainfall infiltration reduces soil suction. From Fig.2, it can also be seen that tension meter Z1 was arranged in slope foot, matric suction of Z1decreased under the action of water infiltration. Tension meter of Z1、Z2、Z3、Z4 and Z5 all decreasing, however, tension meter Z1, Z2, Z3 rapidly reduced to zero after 3 rainfall, tension meter of $\mathrm{Z} 5$ was $-5 \mathrm{kPa}$, because the slope landslide happened and suction distribution of slope were affected by antecedent rainfall.

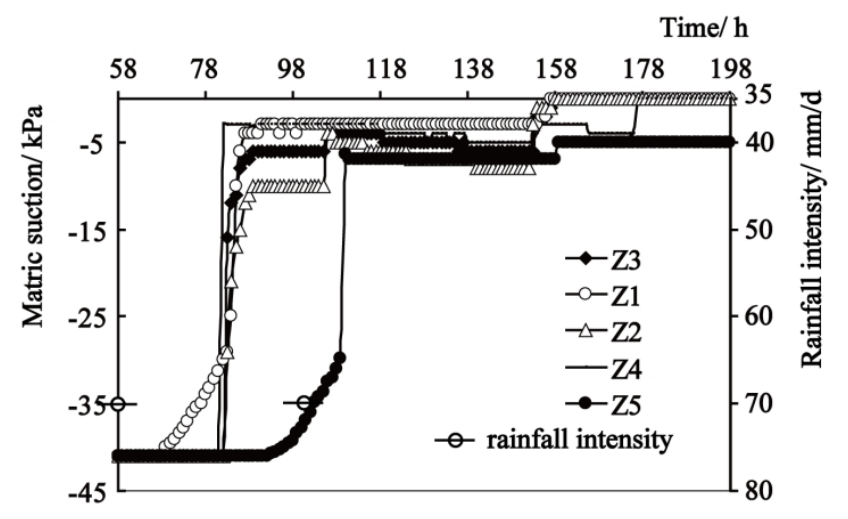

Fig.9 Variations of matric suction under antecedent rainfall

\section{Water content changes for antecedent rainfall}

The measured water content results for specimens are shown in Fig.10. Water content are the upper layer changes from the initial value of $19.5 \%$, that is, water content change occurred at the upper layer of slope. The volumetric water content increased during rainfall. The amount of antecedent two rainfalls is about $192.5 \mathrm{~mm}$, after the third rainfall, the water content below $2 \mathrm{~m}$ continued to increase, however, the influenced depth was less than $0.6 \mathrm{~m}$.

Fig.10 shows that water contents at depths of $0 \mathrm{~cm}, 20 \mathrm{~cm}, 40 \mathrm{~cm}$ and $60 \mathrm{~cm}$ were $24.9 \%, 23.8 \%$, $21.1 \%$ and $19.5 \%$,respectively. These results reveal that water infiltration did occur in the soil.

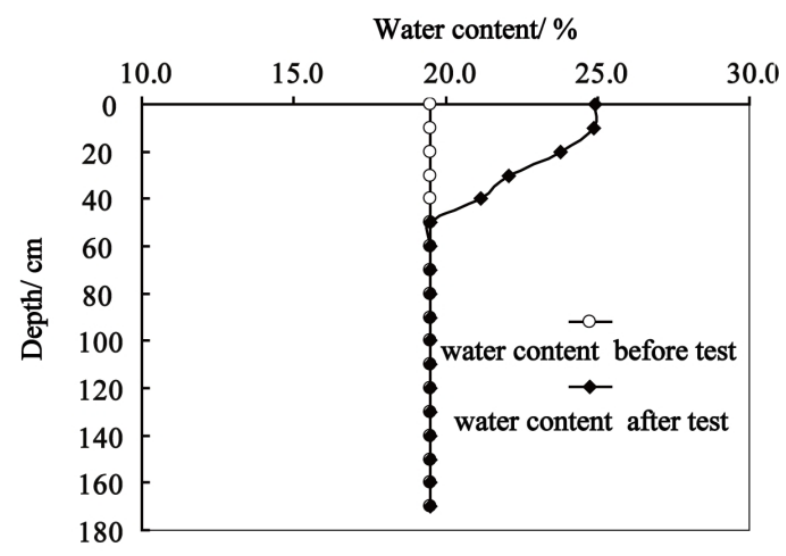

Fig.10 Variations of water content under antecedent rainfall 


\section{Cracks changes for antecedent rainfall}

Fig.11 shows that cracks of process and landslide under the action of antecedent rainfall, model test research shows that under the action of antecedent rainfall is basically shallow sliding slope landslide development process, at the beginning of the slope slide is given priority to with block damage, the landslide process is given priority to with flow slide destruction with rainfall, then, flow slide destroyed when saturated soil at top of slope. First, tiny cracks generated at the foot of the slope, toe cracks generated at the discontinuous increasing with the rainfall infiltration continued. Toe discontinuous crack width increasing and the discontinuous crack through the formation of larger cracks with increased rainfall; cracks were triggered toe-third of the height of slope. Rainfall in parts of rain in the form of runoff flow from the surface to the toe of the slope with rainfall infiltration proceeds. Finally, landslide of the slope continues to extend from the bottom to the top of the hill development, the process flow slippery slope to the main slide, landslide of the process to flow slip based.

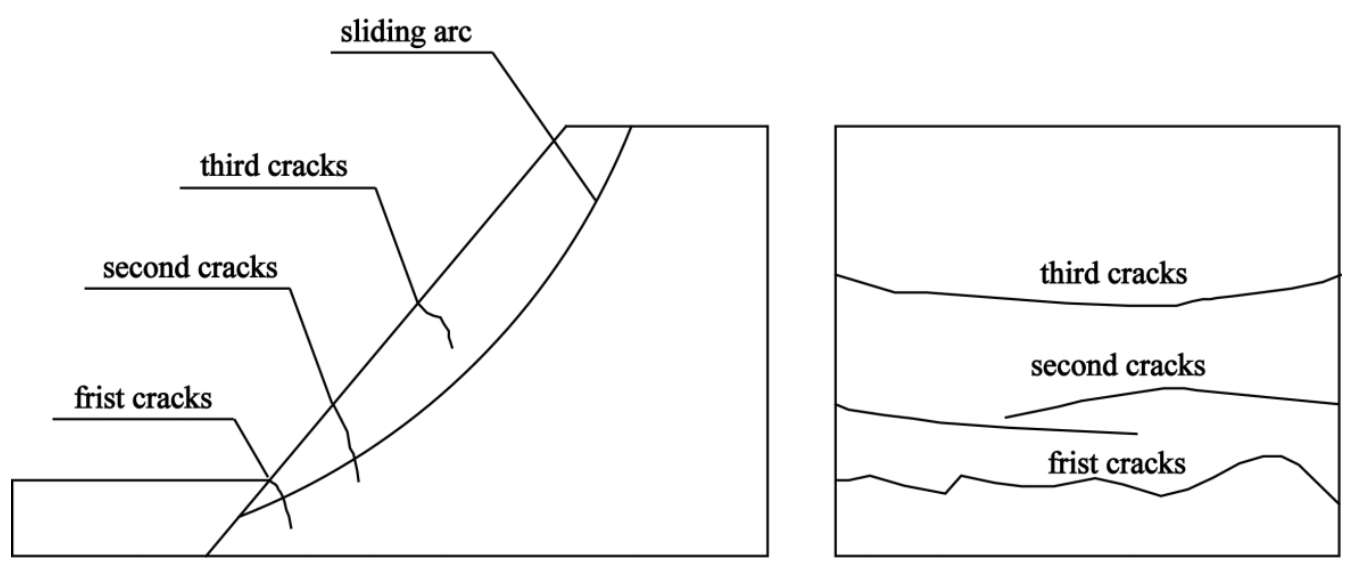

Fig.11 Variations of crack and slip arc under antecedent rainfall

\section{Conclusions}

In this paper, based on the rainfall profile in the area of the reservoir bank near the dam of Longjiang hydropower plant in Yunnan Province of China, the authors investigate the landslide under antecedent rainfall. By using the self-developed experimental apparatus, a model test which simulate the landslide under antecedent rainfall in laboratory have been conducted and the characteristics of the landslide under the antecedent rainfall have been investigated. Based on the above analysis and discussion, the following conclusions can be drawn:

(1) Experimental study of landslide shows that antecedent rainfall is the key factor of landslide, the antecedent rainfall triggered landslide.

(2) Antecedent rainfall causes on soil slope instability, because the shear strength that is 
present in unsaturated soils due to matric suction is lost as a result of rainwater infiltration into the soil.

(3) Antecedent rainfall reduces soil suction and increases the pore-water pressures in soils. Rainfall intensity is $70 \mathrm{~mm} / \mathrm{h}$, matric suction between $-40 \mathrm{kPa}$ and $0 \mathrm{kPa}$.

(4) Antecedent rainfall-induced shallow slope failures in this paper. The influence depth under this rainfall intensity is about $60 \mathrm{~cm}$.

(5) First, tiny cracks generated at the foot of slope, toe cracks generated at the discontinuous increasing with the rainfall infiltration continued. Toe discontinuous crack width increasing and the discontinuous crack through the formation of larger cracks with increasing rainfall, cracks were triggered toe-third of the height of slope.

\section{Acknowledgements}

This research was supported by the National Key Technology R\&D Program (2012BAK10B04), Research Projects in Public Interest of the Ministry of Water Resources of the People's Republic of China (201301033), the Natural Science Foundation of Jiangsu Province of China (BK20130072), The National Natural Science Foundation of China (51309164, 51579154)

\section{References}

[1] ALEOTTI P., 2004. A warning system for rainfall-induced shallow failures[J]. Engineering Geology 73(3), 247-265.

[2] BRAND E W, PREMCHITT J, PHILLIPSON H B., 1984. Relationship between rainfall and landslides in Hong Kong[C]//Proceedings of the 4th International Symposium on Landslides. Toronto: Canadian Geotechnical Society, 377-384.

[3] Brand, E.W., 1992. Slope instability in tropical areas. Proc. of the VI International Symposium on Landslides, Christchurch, vol. 3. Balkema, Rotterdam, pp. 2031-2051.

[4] Ng, C.C.W., Zhan, L.T., 2007. Comparative study of rainfall infiltration into a bare and a grassed unsaturated expansive soil slope. Soils Found47 (2), 207-217.

[5] Corominas, J., 2000. Landslide an climate. Proc of the VIII International Symposium on Landslides, Cardiff. Keynote Paper Published in Electronic Form.

[6] Corominas, J., Moya, J., 1999. Reconstructing recent landslide activity in relation to rainfall in the Llobregat river basin, Eastern Pyrenees, Spain. Geomorphology 30, 79-93. 
[7] Crozier, M.J., 1999. Prediction of rainfall triggered landslides: a test of the antecedent water status model. Earth Surface Processes and Landforms 24, 825-833.

[8] Crozier, M.J., Glade, T., 1999. Frequency and magnitude of landsliding: fundamental research issues. Zeitschrift fu“" r Geomorphologie N.F. 15, 141-155.

[9] Glade, T., Crozier, M., Smith, P., 2000. Applying probability determination to refine landslide-triggering rainfall thresholds using empirical "antecedent daily rainfall model”. Pure and Applied Geophysics 157, 1059-1079.

[10]Govi, M., Mortara, G., Sorzana, P., 1985. Eventi idrologici e frane.Geologia Applicata e Idrogeologia 20 (2), 395-401.

[11]PITTS J., 1985. An investigation of slope stability on the NTI campus, Singapore[R]. Singapore: Nanyang Technological Institute.

[12]TAN S B, TAN S L, LIM T L.,1987. Landslide problems and their control in Singapore[C]//Proceedings of the 9th Southeast Asian Geotechnical Conference. Bangkok, Thailand: Southeast Asian Geotechnical Society, 25-36.

[13]TANG Dong, LI Dianqing, ZHOU Chuangbing, et al., 2013. Slope stability analysis consuidering antecedent rainfall process[J]. Rock and Soil Mechanics34(11), 3240-3248. (In Chinese)

[14] Wieczorek, G.F., 1987. Effect of rainfall intensity and duration on debris flows in central Santa Cruz Mountains, California. In: Costa, Wieczorek (Eds.), Debris Flows/Avalanches: Processes, Recognition and Mitigation. Reviews in Engineering Geology, vol. 7. Geological Society of America, pp. 23-104.

[15] Wieczorek, G.F., Morgan, B.A., Campbell, R.H., 2000. Debris flow hazards in the Blue Ridge of Central Virginia. Environmetal and Engineering Geoscience VI (1), 3-23. 